live singly, eat only the parenchyma of the leaf from the under side and hide by day in dry curled leaves that adhere to the twigs or in some other place of concealment on the branch. In this habit they differ from other Nola larvae that I have met with, which do not hide and eat the leaf from the top side only.

Habitat. Texas (Zeller), Colorado (Grote), Santa Barbara and Ventura Counties, California. It will probably also be found in the intermediate territory in the cañons and arroyos where willows grow.

\section{A Dipterous Parasite of the Toad.}

In the Zoologischer anzeiger, jahrg. 14, no. 379, Dec. I4, '9r, p. 453-455, Duncker describes an interesting case of parasitism. A number of common toads were found in the neighborhood of Kiel with their nares eaten out and their heads swollen in the buccal region. The animals moved about languidly holding their heads down and when kept in confinement rubbed their nares against the walls and floor of the terrarium "as if to relieve themselves of an itching sensation." One of the animals thus confined died and was soon afterwards found completely skeletonized. The moss in which it was buried contained many white fly larvae $(8 \mathrm{~mm}$. long, $2 \mathrm{~mm}$. broad). These soon pupated and in about 4 weeks gave rise to more than 50 flies which proved to be Lucilla sylvarum. Duncker claims that the eggs or very young larvae are deposited in the nares of the toad. The larvae first eat their way backwards to the buccal region and finally devour all the soft parts of the animal, even the ligaments of the bones. He expressly states that it is not the weak and sickly toads which are selected by the flies, since he has found infected specimens that had just sloughed their skins and were to all appearances in good health. Furthermore none of the infected toads appeared to have been wounded.

\section{HENRY WALTER BATES.}

It is not in London alone that the death of Henry Walter Bates will be deplored. He was one of the four entomologists - Wallace, Weismann, and Fritz Müller being the others - who have most distinguished themselves in support of the derivative theory of organic life, and who have gained for it independent evidence from new fields of research with which their names will be indissolubly associated. With the exception of Weismann all are Europeans who gained their inspiration in Brazil, and it was there that Bates was first brought face to face with the most patent facts of mimicry.

The world has admired the unassuning attitude of Darwin and of Wallace, as well as their genius, and the same attitude may be claimed for Bates, whose striking contribution to the philosophy of mimicry was modestly bidden in a systematic essay on the butterflies of the Amazons, the title of which made no reference to the fact. Had it not been accompanied by colored plates specially illustrative of the theory there broached, and had it not appeared in the heat of the Darwinian uprise, it would have lain dormant for many a year. Yet he was the first in explanation of the facts to offer a theory worth a moment's consideration; it has since received no correction and no noteworthy modification, and stands today as clear and satisfactory a statement of the whole matter as has ever since been made.

Bates was born Feb. 8, 1825; at twentythree he left for Brazil where he spenteleven years in collecting. On his return he published his Naturalist on the Amazons, which gained him the post of assistant secretary to the Geographical society, which he held until his death, Feb. I6, I892. His systematic work was mainly in diurnal Lepidoptera and Coleoptera, especially the Carabidae, and, according to McLachlan, he left behind him an incomplete work on the classification of this family besides copious biological notes and 

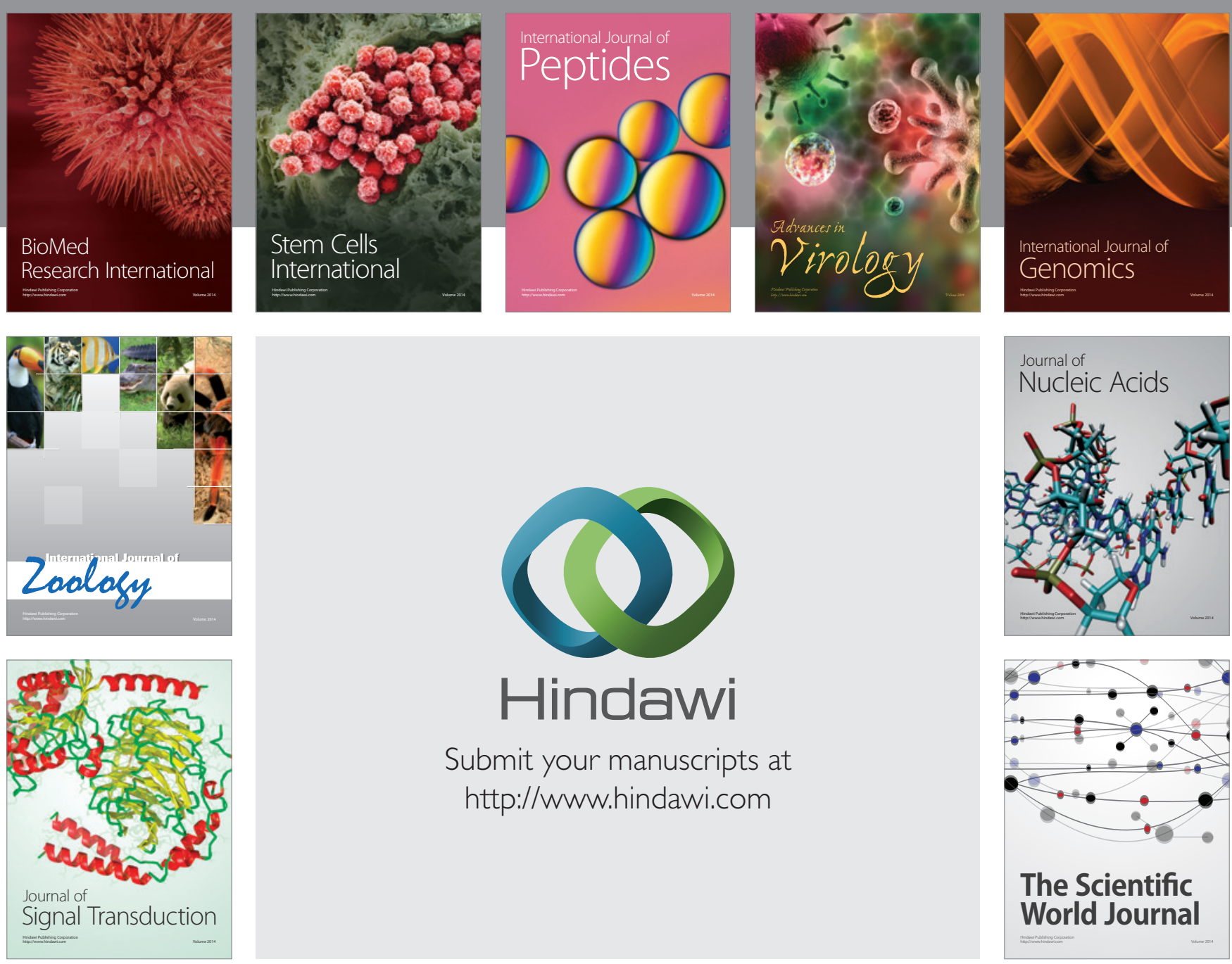

Submit your manuscripts at

http://www.hindawi.com
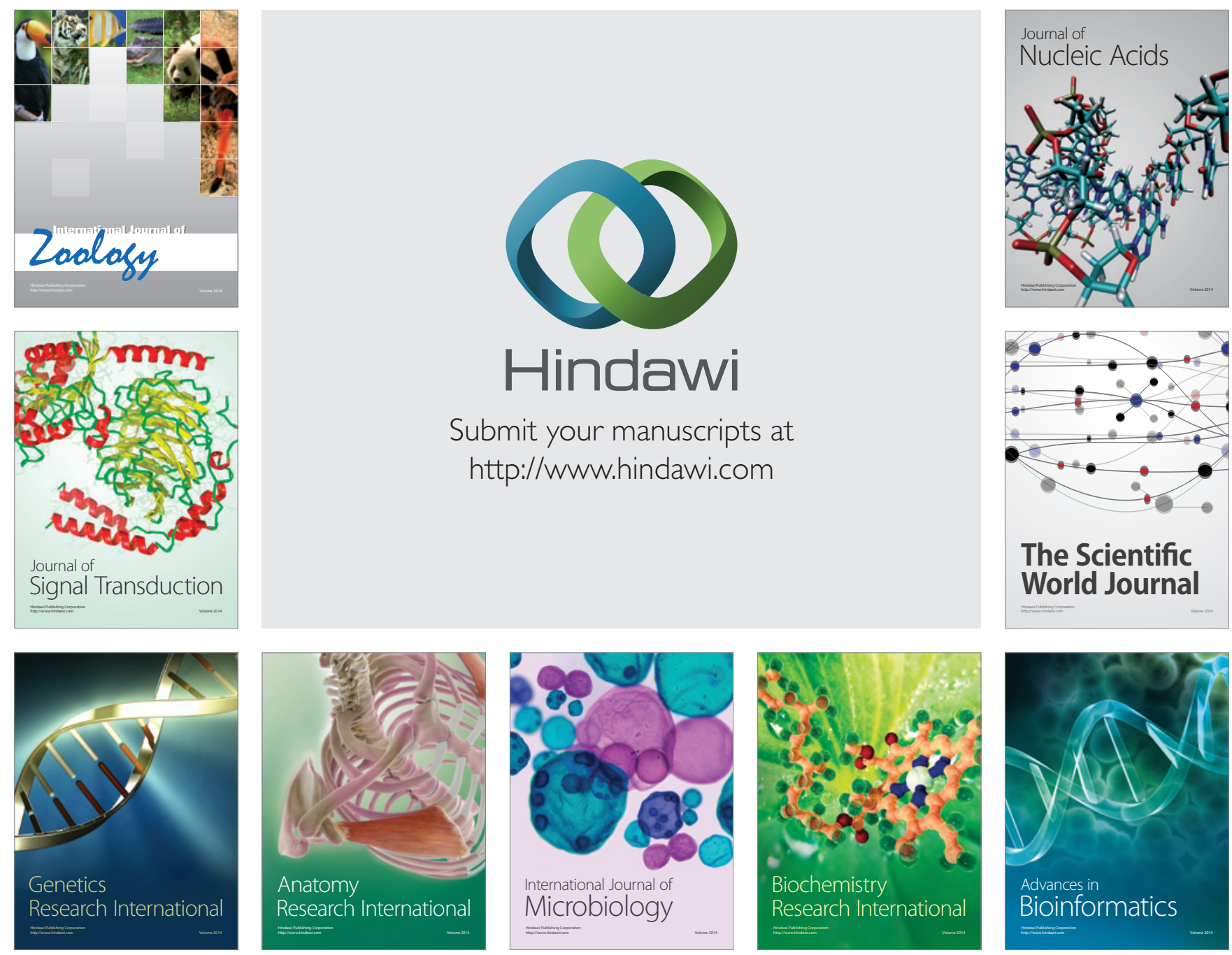

The Scientific World Journal
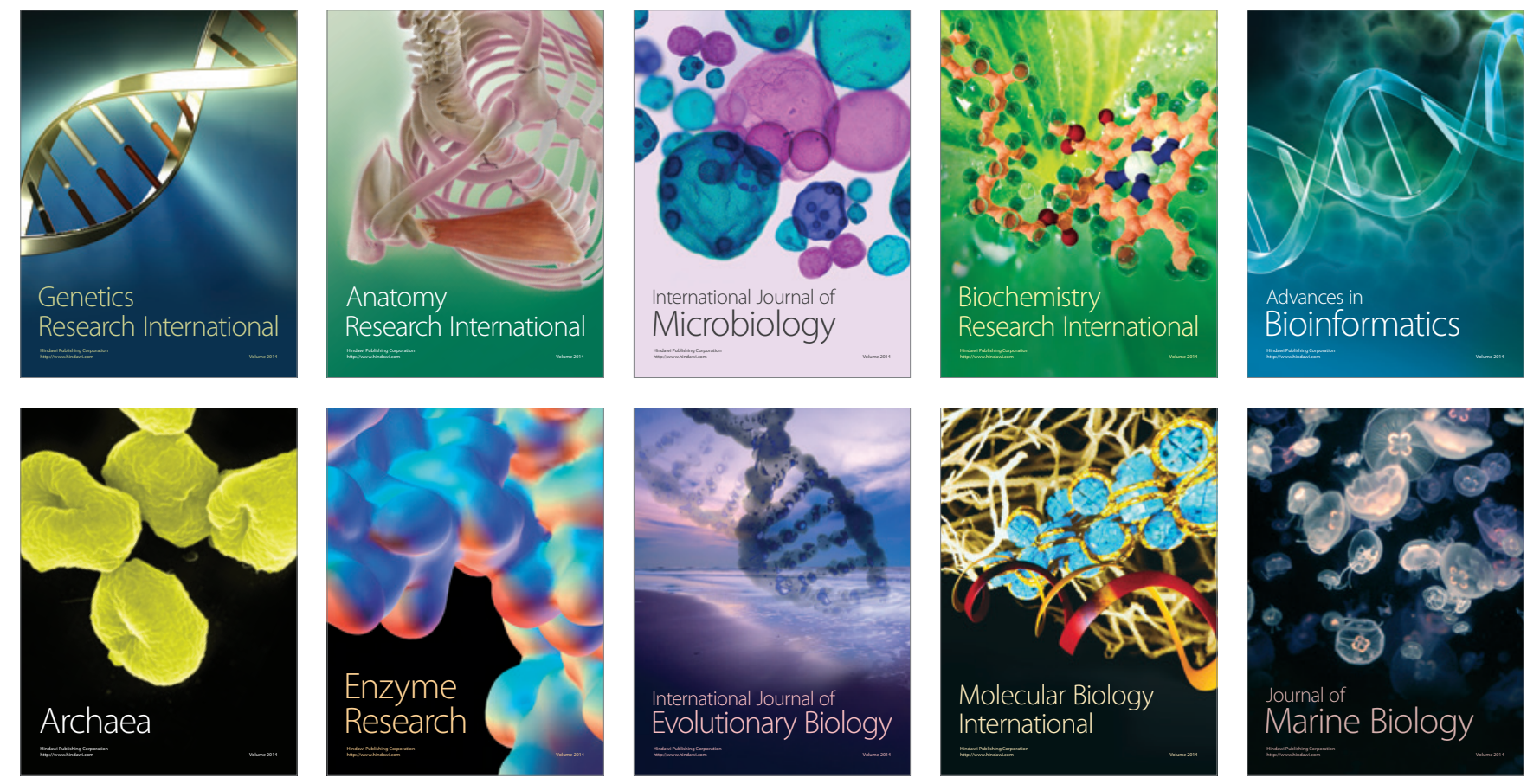